\title{
Vaccination, an individual right, or a collective responsibility? Challenges and opportunities in the $21^{\text {st }}$ century
}

\author{
Mario C. Salinas-Carmona* \\ Department of Immunology Service, School of Medicine and University Hospital, Autonomous University of Nuevo Leon, Nuevo Leon, Mexico
}

For over 200 years, vaccination has contributed to saving human lives from complications and death by infectious diseases. Since the creation of the first vaccine in 1794 by Dr. Edward Jenner in England, which was the origin of immunology, humans have been able to control outbreaks and complications, and prevent the deaths of millions of human beings worldwide. The arrival in the Americas of the vaccine against smallpox created by Jenner, thanks to the talent and creativity of Dr. Balmis in 1806, was the beginning of the benefits of vaccination against this disease in America. The collaborative work of immunologists, some vaccine manufacturers, government officials, and organized society, led by Dr. Carlos Canseco Gonzalez, paid off by achieving the eradication of polio from our continent in recent years ${ }^{1}$.

In the second decade of the $21^{\text {st }}$ century, some of the diseases preventable through vaccination include smallpox, rabies, polio, diphtheria, pertussis, tetanus, measles, hepatitis $\mathrm{A}, \mathrm{B}$ and $\mathrm{C}$, rubella, meningitis by Haemophilus influenzae type b, yellow fever, Japanese encephalitis, herpes zoster, mumps, pneumonia by pneumococcus, diarrhea by rotavirus, human papilloma, varicella, typhoid fever, anthrax, and Ebola, to name a few 1 .

The application of these vaccines varies depending on the country or region of the world since, fortunately, not all infectious-contagious diseases exist in the same manner in all regions of the world. This situation has been changing as a result of the growing migration of people and produce around the world ${ }^{2}$.

The application of vaccines is required in children in almost every country; this way, the government secures a reasonable absence of outbreaks, severe problems, or massive deaths caused by some of the infectious diseases. There are special cases where the dismissal of the application of certain vaccines is justified due to medical reasons and not because of personal convictions. For example: in patients with immunodeficiencies such as severe combined immunodeficiency deficiency, people who are allergic or hypersensitive to certain components present in some vaccines during their manufacturing process, or those individuals who had an anaphylactic shock against certain substance known to be in certain vaccines, in addition to patients who are receiving immunosuppressors like methotrexate. Some of these restrictions or contraindications are relative or transitory according to the clinical situation of each individual.

The industrial procedures for the massive production of vaccines continuously improve and have changed over time, from using products which are derivatives of those same microbial agents, to the productions by the technology of the recombinant DNA of proteins of infectious agents, among other things.

Some countries considered developed suspended vaccination of measles, for example, because they considered it eradicated without considering migration as a source of transmission of infectious diseases ${ }^{2}$.

The application of some vaccines is not exempt from undesirable effects, which range from mild, like irritation and pain in the application site, or hyperthermia and irritability in many cases, yet are transitory and disappear in a day or two after application, to severe collateral effects. Even though cases of attributable death may

\section{Correspondence:}

*Mario C. Salinas-Carmona

E-mail: mario.salinas@uanl.mx
Date of reception: 20-03-2019

Date of acceptance: 26-03-2019

DOI: 10.24875/RMU.M19000032
Available online: 09-08-2019 Medicina Universitaria. 2019;21(2):38-39 www.medicinauniversitaria.org CC BY-NC-ND license (http://creativecommons.org/licenses/by-nc-nd/4.0/). 
occur, its probability is $<1$ in 1 million applications and manufacturers are continuously performing safety tests on their formulas. There are also patients who present undesirable effects classified as mild, such as a cough, persistent or high fever, diarrhea, abdominal pain, a burning limb pain sensation or irritation of the pharynx.

The presence of chemical compounds such as phenol, formalin, mercury, thimerosal, gelatin, and adjuvant, among others, was linked with the presence of illnesses or the presence of febrile seizure, Guillain-Barre syndrome, and autism ${ }^{3}$. This mobilized the manufacturers of vaccines to withdraw the presence of this chemical in the formulations of their vaccines. The author of that article retracted that publication and many scientific articles validated since then repeatedly found the false arguments on which this publication was based ${ }^{4-6}$. These facts, together with religious and philosophical prejudices, contributed to a public disinformation campaign and an increasing resistance to vaccination? ${ }^{7}$. The application coverage of an measles, mumps, and rubella (MMR) vaccine (against MMR) dropped significantly in England and the US. The result of this lack of coverage in susceptible individuals is becoming worse every day since groups of humans of certain age group were deprived of the advantages of vaccination. Hence, there are now cases of pertussis, measles, and diphtheria in the US, Spain, and other countries. Misinformation of a sector of the population and ignorance, combined with a smear campaign against vaccination, as well as a disregard for public vaccination programs, led to an increase in the onset of diseases in non-vaccinated children. This makes it very clear that the individual right of parents over the decision of whether or not to vaccinate their children damaged innocent third parties.

The economic cost of attending to those sick patients who were not vaccinated is very high because this could have easily been avoided with vaccines ${ }^{8,9}$. A clear example of this is the 9000 cases of pertussis which affected North American children in 2012. The mortality in this group was 10 of the non-vaccinated children.

However, beyond the economic costs, the fact that parents decide what is best for their children regarding vaccinations because it is their right to do so, and decide against vaccinations, has generated a polarization in society between those in favor and those against the use of vaccines. From the Public Health Point of View, a serious problem is being created, since public policies in countries promote and procure vaccinations for a susceptible population. For certain viral diseases preventable with vaccines based on an attenuated live virus, immunization of over $80 \%$ of a susceptible population generates herd immunity with a benefit for the community, even the vaccinated people. Health personnel is at professional risk, especially when in a community where there is a large group of susceptible people who were not vaccinated and who have caused measles outbreaks in the past ${ }^{9,10}$.

From an immunological and biotechnological point of view, there are still considerable challenges ahead, such as the prevention through vaccines of malaria, pulmonary tuberculosis, AIDS, mycetoma, and schistosomiasis. To conquer the challenge of the growing resistance to have vaccination accepted as a responsibility and an obligation of a society as a whole, without affecting individual freedom. A global program that correctly informs and educates the population of the benefits of vaccination, and how these are greater than some of the problems which may arise than some of the problems they may create. We have the challenge of preventing infectious diseases with the social responsibility over our individual rights.

\section{Conflicts of interest}

There are no conflicts of interest.

\section{Ethical disclosures}

Protection of human and animal subjects. The authors declare that no experiments were performed on humans or animals for this study.

Confidentiality of data. The authors declare that they have followed the protocols of their work center on the publication of patient data.

Right to privacy and informed consent. The authors declare that no patient data appear in this article.

\section{References}

1. Salinas-Carmona MC. Inmunización y vacunas: la prevención de las enfermedades infecciosas a través de la vacunación. In: La Inmunología en la Salud y la Enfermedad. $2^{\text {nd }}$ ed. Mexico: Panamericana; 2017.

2. Richard JL, Masserey Spicher V. Large measles epidemic in Switzerland from 2006 to 2009: consequences for the elimination of measles in Europe. Euro Surveill. 2009;14:19443.

3. Wakefield AJ, Murch SH, Anthony A, Linnell J, Casson DM, Malik M, et al. Ileal-lymphoid-nodular hyperplasia, non-specific colitis, and pervasive developmental disorder in children. Lancet. 1998;351:637-41.

4. Fitzpatrick M. MMR: risk, choice, chance. Br Med Bull. 2004;69:143-53.

5. Benedicto AS. La supuesta asociación entre la vacuna triple vírica y el autismo y el rechazo a la vacunación. Gac Sanit. 2012;26:366-71.

6. Taylor LE, Swerdfeger AL, Eslick GD. Vaccines are not associated with autism: an evidence-based meta-analysis of case-control and cohort studies. Vaccine. 2014;32:3623-9.

7. Ropeik D. How society should respond to the risk of vaccine rejection. Hum Vaccin Immunother. 2013;9:1815-8.

8. Zhou F, Santoli J, Messonnier ML, Yusuf HR, Shefer A, Chu SY, et al. Economic evaluation of the 7-vaccine routine childhood immunization schedule in the United States, 2001. Arch Pediatr Adolesc Med. 2005;159:1136-44.

9. Chen SY, Anderson S, Kutty PK, Lugo F, McDonald M, Rota PA, et al. Health care-associated measles outbreak in the united states after an importation: challenges and economic impact. J Infect Dis. 2011;203:1517-25.

10. Sugerman DE, Barskey AE, Delea MG, Ortega-Sanchez IR, Bi D, Ralston KJ, et al. Measles outbreak in a highly vaccinated population, San Diego, 2008: role of the intentionally undervaccinated. Pediatrics. 2010;125:747-55. 